\title{
Reading discussion groups for teachers: connecting theory to practice
}

\author{
Ben Fenton-Smith and Christopher Stillwell
}

\begin{abstract}
This article explores how teachers can engage with ideas (research findings, theory, and professional knowledge) through participation in a reading discussion group. Focusing on one group formed by English language teachers at a Japanese university, the study employs survey data, attendance statistics, and observational notes regarding the group's meetings over one school term to investigate the relative merits of six discussion formats, varied according to the type of text discussed (conference presentation slide handout, opinion piece, plenary address video, book chapter, book review, and transcribed interview) and, in one case, the participant make-up (an author was invited to discuss his own work). The paper also identifies group management practices that are most effective for facilitating participation.
\end{abstract}

\section{Introduction}

There is a gap in the field of English language teaching, with professional literature (in the form of theory and research) on the one side and classroom practice on the other. Though not widely researched, one does not have to look far for references to the divide between theory and practice (see, for example, Johnson 1996). Studies on how language teachers engage with research ${ }^{1}$ are more plentiful, and they typically show that language instructors have difficulty perceiving the utility of empirical research in classroom practice (McDonough and McDonough 1990 and Zeuli 1994), and that teacher uptake of research literature is further hampered by its sheer volume, ambiguity, and physical/conceptual inaccessibility (Hemsley-Brown and Sharp 2003). Contributing to the problem is what Bartels (2003) notes as the tendency of language teachers and language researchers to read professional literature differently, and their mutual intolerance of each other's discourse: while teachers value practical connections to classroom instruction, academics place far greater importance on the presentation of objective evidence for claims, with perhaps little concern for classroom applications. A recent analysis of 505 teachers' responses to research shows the impact of these differences: 84.4 per cent did not read research on more than an occasional basis. The most cited reasons for this, unsurprising to anyone in the 
profession, are: lack of time, lack of access to books/journals, lack of applicability to the classroom, difficulty of understanding, and lack of interest (Borg 2009).

To address these issues, a number of provisions necessary to facilitate teachers' effective use of research findings (applicable, no doubt, to any other forms of professional literature as well) have been proposed, such as:

- sustained opportunities to 'conjoin their understanding of studies with their knowledge of teaching' (Zeuli 1994: 54);

- 'extended time to translate the meaning of research findings for their own local contexts, personal theories, and ways of doing things' (Bartels op.cit.: 750);

- 'settings of collaboration and mutual support' that are utilitarian and inspirational, providing immediate payoffs and meeting local needs (Hemsley-Brown and Sharp op.cit.: 461).

In sum, the works cited above suggest that attempts to close the gap between professional literature and practice in ELT are more likely to succeed if they are collaborative, sustained, organized, local, useful, convenient, accessible, and timeefficient. Still, these authors offer few concrete strategies for putting these principles into practice. In a footnote, Borg (op.cit.: 389) passes the baton to his readers, positing an audience of 'academic readers ... in a position to use the insights from this study to support research engagement among the teachers they work with'.

\section{The reading discussion group}

This paper explores one concrete way of supporting teacher engagement with professional literature in a fashion that is collaborative, local, and accessible: a reading discussion group undertaken by EFL teaching staff for EFL teaching staff. Supported by reflective data collected from the participants, attendance statistics, and detailed post-session notes, the paper explores the techniques employed in one such group at a small university in Japan.

The group was comprised of (predominantly non-Japanese) teaching staff who met for 1 hour a fortnight over two 13-week semesters during a 4-year period. It was initiated by the authors of this paper, who were EFL instructors at the university during that 
period. Participants typically had 1 week to read a selected text, copies of which were made available to all. Texts were often selected by one of the authors, though there were numerous occasions when other participants selected material. Although one participant was usually nominated discussion leader, discussions were completely unstructured, without any discussion questions selected in advance.

This paper will focus on a 3-month period at the end of the group's third year. As the reading discussions were a non-mandatory professional development activity open to any of the over 50 EFL teachers in the school's English Language Institute, as well as any other teachers throughout the university, participants varied from one meeting to the next. During this particular period, 7 teachers attended regularly and 13 additional participants attended at least once.

In light of the findings that teachers are disinclined to engage with research and theory, the readings selected for discussion during the period of time analysed in this paper came from a range of genres of academic discourse that reinterpret research and theory in a fashion thought to be more useful, convenient, accessible, and timeefficient:

1 PowerPoint handout from a conference presentation

2 opinion piece from a journal

3 DVD of a plenary address

\section{4 book reviews}

5 published interview

6 published research.

It was also surmised that the opportunity to discuss a reading directly with a published researcher may stimulate participation, and on that basis one session was conducted with the author of the text present (6). This paper explores the effect that varying the discussion in the above ways had in terms of attracting participants and fostering engagement with professional literature. 


\section{Methodology}

Immediately after each session the authors convened to write up detailed notes. In addition the 22 teachers who had attended at least one session over the course of the year were asked to complete an anonymous online survey. Twenty-one responded, five of whom had only attended sessions during the earlier part of the year not focused on in this study. The authors themselves did not participate.

The survey asked teachers to (1) report which sessions they had attended, (2) express their interest in having certain discussion formats ${ }^{2}$ repeated (regardless of whether they had attended or not), and (3) express their preferences with regard to how the discussions ought to be managed. Most questions offered space for additional comments, and respondents were free to answer as many or as few questions as they wished.

\section{Research questions}

In our analysis of the data, we sought to find answers to two questions:

1 What are the inherent strengths and weaknesses of the six formats of reading discussions?

2 How do teachers prefer reading discussions to be conducted?

\section{Data on attendance and interest}

The following tables provide basic data on attendance and interest for each of the sessions. Table 1 gives an overview of the discussion formats. It also contains raw participant numbers as a rough indication of each format's appeal, while data on the number of new participants each discussion brought in provide another means of inferring a format's drawing power.

\section{Table 1: Format Features and Attendance}




\begin{tabular}{|l|c|c|c|}
\hline \multicolumn{1}{|c|}{ Format (Topic) } & $\begin{array}{c}\text { Total \# of Teachers } \\
\text { Attending* }\end{array}$ & $\begin{array}{c}\text { \# of First-time } \\
\text { Attendees (for the } \\
\text { semester) }\end{array}$ & Date \\
\hline $\begin{array}{l}\text { PowerPoint (SLA in the } \\
\text { classroom) }\end{array}$ & 10 & - & October 1, 2008 \\
\hline Opinion piece (Testing) & 9 & 2 & October 15, 2008 \\
\hline $\begin{array}{l}\text { DVD (Language learning } \\
\text { strategies) }\end{array}$ & 7 & 3 & October 29, 2008 \\
\hline $\begin{array}{l}\text { Text with Author Present } \\
\text { (Adapting materials) }\end{array}$ & 13 & 0 & November 20, \\
\hline Book reviews (Various) & 7 & 2008 \\
\hline Interview (Leo van Lier) & & & December 3, 2008 \\
\hline
\end{tabular}

*Note: These numbers include the 2 authors of this paper, who attended every session.

Table 2 shows survey respondents' expressed interest in repeating a particular format in the future (regardless of whether the respondent had attended that session).

Table 2: Interest in repeating a format (all respondents)

'I would like to repeat this discussion format next semester:'

\begin{tabular}{|l|c|c|c|c|c|c|}
\hline Format & $\begin{array}{c}\text { \# of } \\
\text { Responses }\end{array}$ & $\begin{array}{c}\text { Strongly } \\
\text { Disagree }\end{array}$ & Disagree & Neutral & Agree & $\begin{array}{c}\text { Strongly } \\
\text { Agree }\end{array}$ \\
\hline PowerPoint & 20 & $5 \%(1)$ & $20 \%(4)$ & $45 \%(9)$ & $20 \%(4)$ & $10 \%(2)$ \\
\hline Opinion piece & 21 & - & - & $9.5 \%(2)$ & $52.4 \%(11)$ & $38.1 \%(8)$ \\
\hline DVD & 19 & $5.3 \%(1)$ & $10.5 \%(2)$ & $26.3 \%(5)$ & $36.8 \%(7)$ & $21.1 \%(4)$ \\
\hline Author present & 20 & - & $5 \%(1)$ & $5 \%(1)$ & $40 \%(8)$ & $50 \%(10)$ \\
\hline Book reviews & 21 & $4.8 \%(1)$ & - & $33.3 \%(7)$ & $47.6 \%(10)$ & $14.3 \%(3)$ \\
\hline Interview & 21 & - & - & $28.6 \%(6)$ & $47.6 \%(10)$ & $23.8 \%(5)$ \\
\hline
\end{tabular}


Table 3 provides further detail by summarizing only the responses from teachers who had attended a particular session.

\section{Table 3:}

\section{Interest in repeating a discussion format (format attendees only)}

'I would like to repeat this discussion format next semester:'

\begin{tabular}{|l|c|c|c|c|c|c|}
\hline Format & $\begin{array}{c}\text { \# of } \\
\text { Responses }\end{array}$ & $\begin{array}{c}\text { Strongly } \\
\text { Disagree }\end{array}$ & Disagree & Neutral & Agree & $\begin{array}{c}\text { Strongly } \\
\text { Agree }\end{array}$ \\
\hline PowerPoint & 4 & - & - & $50 \%(2)$ & $25 \%(1)$ & $25 \%(1)$ \\
\hline Opinion piece & 7 & - & - & - & $43 \%(3)$ & $57 \%(4)$ \\
\hline DVD & 5 & - & - & - & $60 \%(3)$ & $40 \%(2)$ \\
\hline Author present & 9 & - & - & - & $33 \%(3)$ & $67 \%(6)$ \\
\hline Book reviews & 5 & - & - & $60 \%(3)$ & $40 \%(2)$ & - \\
\hline Interview & 5 & - & - & - & $40 \%(2)$ & $60 \%(3)$ \\
\hline
\end{tabular}

In the following section, we address the first research question by exploring the strengths and weaknesses of each of the six reading discussion formats.

\section{Discussion of formats}

\section{PowerPoint handout}

PowerPoint slides from a presentation by a prominent TESOL academic were a genre of interest for the first discussion of the semester because the provenance of such slides would assure participants that the content was worthy, while requiring minimal preparation prior to attending the discussion. These slides can occasionally be acquired at conference presentations, on conference-related web pages, or the presenters' own websites. The PowerPoint content was from a talk that summarized 
the essentials of SLA for the language classroom. Teachers in the thick of teaching do not often find occasion to revisit such dense theoretical material, but this discussion created a forum in which teachers could explore how the various theories might apply to their classrooms.

As Table 1 shows, this session had the second highest attendance of any meeting, although this may be because it was the first of the semester. Table 2 shows that only 30 per cent of participants agreed/strongly agreed that they 'would like to use other PowerPoint handouts for reading discussions next semester', with one respondent stating 'that it would be difficult to grasp the full intended meaning of the discussion' of the slides outside the context of the presentation. However, Table 3 shows that no one who participated in the PowerPoint discussion opposed doing it again. Furthermore, our post-discussion notes identify a benefit to the lack of 'full intended meaning', as it created a knowledge gap that challenged participants to collectively interpret the presenter's intentions. For instance, discussion of the term 'monitor theory' began with an erroneous suggestion that it referred to teachers' styles of giving feedback to students, but the group gradually came to the understanding that it referred to a theory of Stephen Krashen, and then reconstructed the theory from their collective professional memory. As this example illustrates, the breadth but lack of depth of PowerPoint handouts can stimulate collaborative recall and analysis of a range of topics, while promoting spontaneous participation even by those who have not read the piece in advance.

\section{Opinion piece}

Most journals are not limited to research articles. Many contain opinion forums (for example ELT Journal's 'Point and counterpoint', TESOL Quarterly's 'Research and teaching issues', Modern English Teacher's 'It made me think’) which are typically brief, ‘big picture’-oriented, non-statistical, and accessible. The group discussed a 2005 'Point and counterpoint' containing Brian Tomlinson's 'personal view of language testing' (Tomlinson 2005a: 39), Neus Figueras’ critique of it (Figueras 2005), and Tomlinson's defense (Tomlinson 2005b). Though testing is usually the domain of the statistically-proficient, the debate structure of these short pieces elicited input from every participant, roughly three-quarters of whom had no formal testing background. 
Out of all the survey participants, 90.5 per cent either agreed or strongly agreed that they would like to read opinion pieces in future sessions: the highest rating of all genres surveyed (Table 2). As one put it, 'opinion pieces certainly get people to talk and talk'. Based on our notes, we can infer a number of reasons why the piece worked so well. As opposed to many other journal articles, the genre did not require in-depth analysis of figures and charts or specialized knowledge of the field; practitioners rather than experts were the target audience. The nature of the genre freed the author to expound on big picture issues without the constraint of fine-grained research-based justification, and this promoted discussion of major ELT issues without having to wade through academic minutiae (a discussion group killer). Ironically, Tomlinson made these very points in defending himself against Figueras: 'I wrote a polemical article aimed at stimulating teachers to think. Neus has written an over-referenced academic article aimed at defending testers’ (Tomlinson op.cit.: 55). The controversial but accessible nature of the pieces drew participants in, providing non-experts the opportunity to participate in the debate, and it exposed latent fault lines in the group ('testers vs. non-testers'), which stimulated heightened interaction.

\section{Video}

A DVD of a conference plenary is a unique form of 'professional literature' which 58 per cent of survey respondents indicated they would like to repeat. Having a discussion group focus on pre-selected segments invites participation and critical viewing in a way that an ordinary presentation cannot. Our post-discussion reflection found that the unique nature of this genre had many effects on the group's discussion: (1) because time constraints made it necessary for excerpts to be chosen in advance, the discussion leader became a benevolent dictator who had to guide discussion and decide which parts of the content to reveal when, and (2) it constrained participants to focus directly on recently viewed segments, thus limiting the extent to which discussion could veer off topic (which survey data revealed was an occasional source of irritation for some members of the group).

Drawbacks to the format included: first, a DVD, unlike a written text, provided nothing for participants to refer to after the discussion was over, and second, for much of the meeting time participants sat in silence absorbing the input, which 'takes away from our discussion somewhat' according to one participant. Potential solutions 
include having the discussion leader provide a handout to supplement viewing and having participants take turns watching the DVD privately, though these solutions may diminish the appeal of the genre in terms of advanced time and preparation needed.

\section{Text with author present}

One way to increase teacher engagement with any genre of professional literature is to create opportunities to discuss it with the author. Although many institutions have little capacity to attract well-known authors for visits, there are creative ways to make it happen: tapping into staff members’ professional networks, joining forces (and budgets) with other professional organizations, and sending invitations to scholars scheduled to attend nearby conferences are three methods we have used. Three renowned ELT academics have attended the sessions and discussed their work in the group: Rod Ellis, Paul Nation, and, during the data collection period, Brian Tomlinson. Each time the scholar suggested an article or chapter they had authored that was short, recent, and relevant to English teachers. Following their visits, the guests typically commented on the benefits of such a reading discussion group for practising teachers and visiting scholars alike. In Paul Nation’s words (personal communication, 27 October 2009), 'At least now I know 9 teachers read my article!'

Feedback from the teachers strongly supports the initiative: 90 per cent agreed or strongly agreed they would like to discuss readings with authors again (Table 2). Furthermore, this session had the highest attendance of all meetings (Table 1), probably due to the 'celebrity' factor of the well-known academic. Participant feedback and our notes suggested six positive ways that the visits affected the group:

1 the discussion was more free, perhaps because participants were keen to access the guest's expertise rather than stick to the text;

2 the text came to life as the author pointed out negatives in his own work and further explained points of interest;

$\mathbf{3}$ some participants appeared to have read the text more closely, perhaps to make the most of the opportunity;

4 several new participants joined (Table 1), with a few returning to later sessions; 
5 the workplace status of the discussion group was raised;

6 networking opportunities were provided.

Two negatives were identified: first, some participants spoke less than usual, probably in deference to the guest, and second, the face-threatening possibilities of the situation resulted in less criticism of content than usual. In subsequent sessions with guest authors, various strategies have helped to deal with this, including having a strong moderator, taking questions in advance, letting the guest know it is not his/her responsibility to do all the talking, and asking the guest to start off with a question for the audience.

\section{Book reviews}

Book reviews can help a reader gauge whether an author is worth further investigation and they offer a short cut for keeping current with developments in the field. We selected three book reviews (see References section: Lightbown 2008; Littlewood 2008; Rubio 2008) to cover a range of variables: length of review, eminence of reviewer/book/journal, publication date of the book (classic to current), authorship (single author to edited volume), and relevance of the book to English teachers.

Like PowerPoint handouts, book reviews provide snapshots, once-removed, of broad academic landscapes. Their brevity had dual benefits: (1) less reading time and (2) knowledge gaps to be filled through discussion. During the session, the variety of topics covered in the brief reviews led the group's conversation to range across psychology, practice, problems in SLA, the birth of communicative language teaching, 'notional' versus 'functional' syllabi, and more. This plurality of topics led to a democratic spread of participation, because the reading material was not captive to any one participant's expertise.

In the survey this genre was not received well: though 61.9 per cent of all respondents expressed a desire to read and discuss reviews in the future (Table 2), only 40 per cent of those who actually attended the session wished to do so again (Table 3). Given that those who joined a discussion of a particular genre typically expressed interest in doing so again, a 60 per cent neutral rating for book reviews is underwhelming. Also of note is that book reviews had the lowest attendance, and was the only format that 
failed to attract any first-time attendees (Table 1).

Analysis of our notes reveals two possible reasons for the relative unpopularity of the format. First, reading texts about texts may have confused the discussion. One participant expressed uncertainty whether the purpose was 'to have a critical perspective of the review itself, or the book being reviewed?' In addition, others noted a danger of taking too much stock in this 'once-removed' genre. For example, the review of Michael Long states: 'the author concludes that recasts are an effective form of feedback that facilitate acquisition and can be more effective than explicit feedback, at least for certain language targets' (Rubio op.cit.: 480). A teacher may conclude that recasts are better than explicit feedback, but a close reading of the indefinite article 'an', the modal verb 'can', and the qualifier 'for certain language targets' reveals the risk of drawing broad conclusions from second-hand accounts of research.

\section{Interview}

Academic interviews found in many journals and teacher publications are an interesting hybrid genre, since they are produced as spoken conversation but appear as formal written texts. As transcriptions of spoken discourse tend to be shorter and less dense than written academic papers, they can be easy to read and offer the possibility of making 'difficult' scholars accessible (as shown in our session, in which an interview with Leo van Lier by Cots and Tusón 1994 was discussed). Clarity is further ensured by the fact that, unlike other types of journal articles, the interviewer acts as mediator between the scholar and readership. There is a certain pressure on the scholar to make him/herself understood, in real time, to this representative of the wider audience.

Many interviews consist of wide-ranging questions, and therefore provide a good introduction to a scholar's work, allowing the reader to decide if further exploration is warranted. The interview questions also may make both the reading and discussion processes more manageable. As signposts of content to come, questions empower the reader to skip over parts of little interest. As topic dividers, questions organize the text so that reading one part is not dependent on reading others. Our notes reveal that these advantages transferred to the discussion itself, facilitating smooth leaps from one 
issue to another as disparate sections of text were easily referenced. The genre also liberates the interviewee to make polemical statements with no expectation of supporting evidence, as when van Lier states that 'linguistics generally has been taught in a very decontextualised way' (ibid.: 55). At various times in the discussion, these types of statements were highlighted by participants, serving as stimulating discussion starters. Significantly, 71.4 per cent of participants surveyed expressed a desire to revisit the interview genre in later discussions.

\section{Practical considerations}

In order to answer the second research question, 'How do teachers prefer reading discussions to be conducted?' survey respondents were asked to anonymously share their thoughts on the management of the group. The following represents practices that may be crucial for the success of reading discussion groups in general.

1 Distribute the responsibility. Having different group members take the lead for discussions facilitates greater participation. Sixty-two per cent preferred that material be selected by various group members, and 77 per cent stated that selecting material should not be solely the responsibility of the group's organizers.

2 Provide structure and allow a core group of 'leaders' to emerge._Despite participants' expressed support for distributed responsibility, relatively few were interested in selecting content themselves ( 38 per cent), leading discussions on material they had chosen (38 per cent), or leading discussions on material chosen by someone else (14 per cent). Thus, it is likely that the continued existence of a group will depend on the efforts of a handful of individuals willing to take an active role in scheduling sessions, identifying interesting material, and leading discussions.

3 Respect the clock. Finding an appropriate time to meet and adhering to the schedule are of great importance. Seventy-five per cent of the participants selected 60 minutes as the ideal length for a discussion and 48 per cent agreed that 'A cut-off time should be enforced'. In addition, the 12 responses to an open-ended prompt seeking reasons for not attending more often stated that lack of time (5), schedule conflicts (5), and general tiredness (2) were obstacles.

$4 \mathrm{~A}$ soft touch is best. Few respondents felt that discussion leaders needed to call on quiet attendees ( 24 per cent), or curtail those who spoke a lot (20 per cent). Only 34 per cent felt that 'People should not be able to participate in discussions without having read the material in advance'. As one respondent commented, 'Even without having 
read, people can still contribute or at least pick up some useful knowledge by listening.'

\section{Conclusion}

Though reading discussion groups are far from commonplace in the language teaching workplace, the challenges are surmountable. Freeman (1996) is right to question whether 'the prevailing language and genre of research truly serve[s] teachers in articulating what they know about teaching' (p. 106); but we would argue that the key is to realize that there are more academic genres than journal articles and book chapters, and that discussion among teachers can make connections between theory, research, and practice possible. Would-be discussion group organizers should take heart-it only takes two to talk!

\section{Notes}

1 In using the term 'engage with research', we follow Borg (2009: 358), who clarifies that teachers do so 'through reading'. However we use the term 'literature' to encompass platforms for delivery of content that are not strictly limited to the page, such as videotaped presentations.

2 We use the term 'discussion format' to cover both the type of text (for example book review) and, in one case, mode of interaction (discussion with the author present).

\section{References}

Bartels, N. 2003. 'How teachers and researchers read academic articles'. Teaching and Teacher Education 19/7: 737-53.

Borg, S. 2009. 'English language teachers' conceptions of research'. Applied Linguistics 30/3: 358-88.

Cots, J. and A. Tusón. 1994. 'Language in education: an interview with Leo van Lier'. Sintagma 6: 51-65. 
Figueras, N. 2005. 'Testing, testing, everywhere, and not a while to think'. ELT Journal 59/1: 47-54.

Freeman, D. 1996. 'Redefining the relationship between research and what teachers know' in K. M. Bailey and D. Nunan (eds.). Voices from the Language Classroom. Cambridge: Cambridge University Press.

Hemsley-Brown, J. and C. Sharp. 2003. 'The use of research to improve professional practice: a systematic review of the literature'. Oxford Review of Education 29/4: 44970.

Johnson, K. 1996. 'The role of theory in L2 teacher education'. TESOL Quarterly 30/4: 765-9.

Lightbown, P. 2008. Review of the book Practice in a Second Language: Perspectives from Applied Linguistics and Cognitive Psychology. Language Testing Research 12/2: 313-6.

Littlewood, W. 2008. 'Thirty years later: Henry Widdowson's Teaching Language as Communication'. International Journal of Applied Linguistics 18/2: 212-7.

McDonough, J. and S. McDonough. 1990. 'What's the use of research?' ELT Journal 44/2: 102-9.

Rubio, F. 2008. Review of the book Problems in SLA. The Modern Language Journal 92/3: 479-80.

Tomlinson, B. 2005a. 'Testing to learn: a personal view of language testing'. ELT Journal 59/1: 39-46.

Tomlinson, B. 2005b. 'A response to Neus Figueras'. ELT Journal 59/1: 55-6.

Zeuli, J. 1994. 'How do teachers understand research when they read it?' Teaching and Teacher Education 10/1: 39-55.

\section{The authors}

Ben Fenton-Smith is a lecturer in the School of Languages and Linguistics at Griffith University in Brisbane, Australia. Prior to that, he spent four years as Assistant Director of the English Language Institute at Kanda University of International Studies in Chiba, Japan.

\section{Email: benfento@gmail.com}

Christopher Stillwell spent four years as a senior lecturer at Kanda University of International Studies. He is currently Assistant Director of the Sojo International Learning Center in Kumamoto, Japan.

\section{Email: StillwellC@aol.com}

